\title{
Propeller Perforator Flaps in Distal Lower Leg: Evolution and Clinical Applications
}

\author{
Alexandru V. Georgescu \\ Clinic of Plastic Surgery and Reconstructive Microsurgery, University of Medicine Iuliu Hatieganu, Cluj Napoca, Roumania
}

Simple or complex defects in the lower leg, and especially in its distal third, continue to be a challenging task for reconstructive surgeons. A variety of flaps were used in the attempt to achieve excellence in form and function. After a long evolution of the reconstructive methods, including random pattern flaps, axial pattern flaps, musculocutaneous flaps and fasciocutaneous flaps, the reappraisal of the works of Manchot and Salmon by Taylor and Palmer opened the era of perforator flaps. This era began in 1989, when Koshima and Soeda, and separately Kroll and Rosenfield described the first applications of such flaps. Perforator flaps, whether free or pedicled, gained a high popularity due to their main advantages: decreasing donor-site morbidity and improving aesthetic outcome. The use as local perforator flaps in lower leg was possible due to a better understanding of the cutaneous circulation, leg vascular anatomy, angiosome and perforasome concepts, as well as innovations in flaps design. This review will describe the evolution, anatomy, flap design, and technique of the main distally pedicled propeller perforator flaps used in the reconstruction of defects in the distal third of the lower leg and foot.

Keywords Soft tissue injuries / Leg / Surgical flaps

\author{
Correspondence: \\ Alexandru V. Georgescu \\ Clinic of Plastic Surgery and \\ Reconstructive Microsurgery, \\ University of Medicine Iuliu \\ Hatieganu, Viilor St., No. 46-50, \\ 400347 Cluj Napoca, Roumania \\ Tel: $+40-722-575963$ \\ Fax: +40-264-438852 \\ E-mail: geordv@hotmail.com
}

No potential conflict of interest relevant to this article was reported.

Received: 10 Jan 2012 • Revised: 31 Jan 2012 • Accepted: 1 Feb 2012

pISSN: 2234-6163 • elSSN: 2234-6171 • http://dx.doi.org/10.5999/aps.2012.39.2.94 • Arch Plast Surg 2012;39:94-105

\section{INTRODUCTION}

Tissue defects still represent a challenge for reconstructive surgeons, which over time used various types of flaps (random, axial, free, perforator flaps) in order to cover them. This paper will describe the evolution, vascular anatomy, tactical design, harvesting technique and clinical applications of the main distally pedicled propeller perforator flaps used in the reconstruction of defects in the distal third of the lower leg and foot.

\section{HISTORICAL EVOLUTION}

Reconstruction of defects in the foot and distal lower leg, with exposed tendons, bone, and/or hardware continues to be challenging, and they generally need flaps coverage [1-5]. In the absence of specific knowledge of the pattern or reliability of the blood supply, the flaps were used initially as random pattern flaps constrained by length-to-width ratios to ensure viability [6]. These flaps are unreliable in the lower leg because of their small dimensions and restrictions in mobility [7]. Moreover, Almeida et al. [8] found a random pattern flap necrosis in $25 \%$ of cases. The axial pattern flap introduced by McGregor and Jackson [9] in 1972, and based on axial blood supply improved the quality of results, but with the sacrifice of a main artery [10-14]. Ger [15], in 1966 and Orticochea [16], in 1972 described the musculocutaneous flaps which became very popular in leg reconstruc- 
tion because of their reliability [17], but with few indications as pedicled flaps in the distal third, because of inadequate reach in this region [18-21]. In 1981, Ponten [22] demonstrated that by including the deep fascia in a cutaneous flap, it can be raised without respecting the length-to-width ratio, but only later other works [23-25] established their anatomical basis. Despite their big advent, the fasciocutaneous flaps proved not to be a very safe procedure for defects in the lower third of the lower leg, as demonstrated by the experience of Chatre and Quaba with a necrosis rate of $25 \%$ [21]. The reappraisal of the works of Manchot [26] and Salmon et al. [27] by Taylor and Palmer [28], which defined the static vascular territories of source arteries as angiosomes, opened new perspectives in flap design. They defined an angiosome as a three-dimensional vascular territory supplied by a source artery and vein through branches for all tissue layers between the skin and the bone, and showed that between neighboring angiosomes there are choked and true anastomotic arteries [28]. Regarding the lower leg, Taylor and Pan [29] found that the branches of the cutaneous vessels radiate after piercing the deep fascia in all directions and interconnect to form a continuous vascular network within the integument.

As a result of this evolution, and following the works published by Koshima and Soeda [30] and Kroll and Rosenfield [31] in 1989, began the era of perforator flaps. At the beginning, the perforator flaps all over the body and also in the lower leg were used as free flaps. Free perforator flaps such as anterolateral thigh perforator flap $[19,32,33]$, tensor fasciae latae muscle perforator flap [19,34], inferior epigastric artery perforator flap [35], thoracodorsal artery perforator flap [36-38], medial sural artery perforator flap [19,39], are mostly used in the lower leg and foot. The revisiting vascular anatomy and the extensive clinical experience has confirmed that also local and regional perforator flaps are safe and reliable in achieving the goals of lower leg reconstruction. As showed by Geddes et al. [40], the lower extremity appears to have the greatest potential for harvesting new or modified perforator flaps. The work of Saint-Cyr and his coworkers, which defined the vascular territories of perforators as perforasomes, helped to better understand the dynamic potential of these perforasomes and their importance in harvesting pedicled perforator flaps in lower leg [41-44]. As the adjacent angiosomes are connected through choke and true anastomotic arteries, between neighboring perforasomes there are direct and indirect linking vessels [43]. According to Rubino et al. [45], the harvesting of a flap based on a single perforator produces a hyperperfusion of this perforator, contributing to the recruitment of adjacent perforasome territories, what can explain the large dimensions of some flaps.

The big popularity gained by the local perforator flaps was due to their main advantages: 1) Sparing of the source artery and underlying muscle and fascia, 2) Combining the very good blood supply of a musculocutaneous flap with the reduced donor-site morbidity of a skin flap, 3) Replacing like with like, 4) Limiting the donor-site to the same area, 5) Possibility of completely or partially primarily closure $[44,46], 6)$ Technically less demanding, because they are microsurgical procedures, but without microvascular sutures, 7) Shorter operating time $[14,18$, $21,42,44,46-49]$.

The concept of propeller flap belongs to Hyakusoku et al. [50], which described in 1991 an adipocutaneous flap designed as a propeller, blood supplied through a random subcutaneous pedicle and rotated 90 degrees. The term was used for the first time to define a perforator flap based on a skeletonized perforator vessel and rotated 180 degrees by Hallock [51] in 2006. The ultimate definition and terminology of propeller perforator flaps was reached by an Advisory Panel of the First Tokyo Meeting on Perforator and Propeller Flaps in 2009 [52]. According with this consensus, a propeller perforator flap is designed as a skin island with two paddles which can be of the same dimensions or with a larger and a smaller one, the demarcation limit between them being the perforator vessel. To be a propeller flap, it has to rotate around the perforator vessel for at least 90 to 180 degrees. A very detailed description of the surgical technique in harvesting propeller perforator flaps in lower leg was presented by Teo [53] in 2006.

Starting from previous works [11-13,25-29,34,54-58], in the last 10 years a large number of surgeons became interested in evaluating the perforator arteries and in performing pedicled perforator flaps in the lower leg [7,14,18-21,33-36,39,41-45,4749,52,53,59-63]. Despite the aforementioned advantages, they were also confronted with some possible drawbacks. The general complication rate with propeller perforator flaps is similar to that observed with free flaps, and consists mainly in complete or partial flap loss due to venous problems $[18,21,44,52,60,61,63]$. In the attempt to reduce the risk of these complications, a lot of artifices in flap design and harvesting technique were imagined. The venous supercharging by including in the flap and suturing a subcutaneous vein can avoid the venous congestion and related complications $[44,46,52,64]$. Teo [53] considers that in designing the flap, to the distance between the perforator and the distal edge of the defect $1 \mathrm{~cm}$ must be added, and half a centimeter to the width, also that the vascular pedicle has to be cleared of all muscular side branches for at least $2 \mathrm{~cm}$, the fascial strands must be divided especially around the venae commitantes, and that the flap should be left in its original position for 10-15 minutes after the tourniquet was released. To reduce the risk of vascular complications due to torsion and buckling of the pedicle, Wong 
et al. [65] suggested that a perforator of $1 \mathrm{~mm}$ diameter should be dissected for a length of at least $3 \mathrm{~cm}$. Probably the main way to diminish the complications rate is the ability to establish the safe vascular limits of a pedicled perforator flap, in other words the real potential dimensions of the flap. While 15 years ago the safe length of a perforator flap was considered to be the distance between two perforators [66-68], nowadays according with the perforasome concept of Saint-Cyr et al. [43], in a perforator flap raised on a single perforator, this one will be hyperperfused resulting in its increased filling pressure with the possibility of recruitment of adjacent perforasome territories [45]. It's easy to understand that as large the vessels' diameter is, as high is the pressure, with bigger potential to open the linking vessels [69]. Based on haemodynamic studies, it was demonstrated that for a perforator in normal anatomic conditions, the flow through it is much smaller than in the source artery, while for the same perforator used as pedicle of a flap the flow through it is still smaller than in the source artery, but much greater than in the former situation $[45,70]$. In each specific region, the greater is the number of perforators, the lesser will be the size of the potential territory of each perforator [18]. This statement is evident in the lower leg, in which the perforators from the posterior tibial artery are small in number, but of larger diameter than the perforators of the anterior tibial and peroneal arteries, which are more numerous, but with a smaller diameter [28]. The problem is if it's possible to establish before or during surgery the size of the perforators and their anatomic and potential territories, to be able to precisely approximate the safer dimensions of the flap. Panse et al. [70] performed a study in the attempt to find a relationship between the necrosis rate of the flap and the rapport between the length of the lower leg and the length of the flap. They found a six times more chance of necrosis for a length of the flap more than one-third of the limbs' length. A lot of methods for preoperative identification of the perforators have been described: handheld Doppler, color Doppler, Duplex ultrasound, arteriography, magnetic resonance angiography, high-resolution computed tomography, but these examinations do not provide informations regarding the flap viability [49]. However, the handheld Doppler probe is adequate for the identification of perforators, while the color Doppler can provide enough data regarding the internal diameter of the perforators [69,71-73]. More important is to find a method able to detect intraoperatively the possible safe dimensions of a flap. In this regard, even if was considered that the fluorescein underpredicts the viability, it was used to predict flaps perfusion $[49,74,75]$. Another method which seems to be more accurate is represented by the indocyanine green near-infrared angiography $[49,76-$ 78]. Another way to prevent complications with local perforator flaps is their use as perforator-plus flaps $[49,79,80]$. That means to design the flap based on dominant blood supply from one or more perforators, but retaining also its base in continuity with the donor-site, which improves both the arterial supply and venous drainage. In preventing the flap necrosis, the design of a flap must respect the vascular axis of flow between the angiosomes, realized through the linking vessels, which follow the axiality of the lower leg [44]. Moreover, because the vascularization close to joints is directed away from them, it means that the long axis of the skin island should be also oriented in the same direction. In the attempt to both diminish the complications rate and increase the vascular territory of a pedicled perforator flap, other long-standing procedures were also proposed, as flap delay $[44,49,52,68,79,81]$, and more recently the flap preexpansion [81].

Finally, the concept of free-style free flaps can be applied also for pedicled perforator flaps, meaning that those flaps can be designed in freestyle fashion based on any major cutaneous perforator [82], and offering a large spectrum of local flaps options flaps [18]. The term "freestyle free flap" was introduced in 1983 by Asko-Seljavaara [83] in a personal communication, to describe a flap harvested in the upper limb after dissection and visualization of a main vessel, and identification of its branches, the flap being blood supplied by those vessels. In 1990 in the hand, and then in 2006 in lower leg, Quaba et al. [18,84] developed the concept of ad hoc perforator flap which is analogue with the freestyle concept, but which considers as irrelevant the knowledge of source vessel and their anatomical variations. The difference consists in the fact that Quaba and Quaba [18] designs the flap in a potential donor territory close to the defect, based on a perforator detected by handheld Doppler signal. In 2003, Mardini et al. [85], and in 2004, Wei and Mardini [86] brought some modifications to the original concept of freestyle free flaps, very similar with the theory of Quaba and Quaba [18], consisting in: incision of only one flaps' edge at the beginning, no need to visualize the source vessel of the perforator, the identification of the perforator should be done by Doppler preoperative examination, the dissection of the perforator starting from the skin level. Authors from the same collective elaborated in 2009 the main principles in harvesting such a flap, and enlarged their application also as local perforator flaps [87]. Some other surgeons published also their experience with freestyle perforator flaps in various anatomical regions [88-92]. Georgescu et al. [46,91] and Matei et al. [92] published their experience in harvesting perforator flaps in the forearm without performing a preoperative exploration of the perforators, considering that because of the superficial location of the main axial source vessels, there can be a lot of false positive or negative results. They 
conclude that the initial incision of only one edge of the future flap, followed by microsurgical dissection, identification and isolation of the required perforator, represent more important considerations than pre-operatively detecting the perforators for a successful flap in this region. This approach was sustained by Lee [93] in his Invited discussion about the paper of Matei et al. [92]. This concept, which corresponds in part with the freestyle flap described by Asko-Seljavaara [83] except the identification first of the source vessels and its branches, and the freestyle flap described by other authors [84-90], can be extrapolated also for propeller perforator flaps harvested in the distal lower leg, where two main source arteries (anterior and posterior tibial arteries) have a relatively superficial location.

\section{PROPELLER PERFORATOR FLAPS IN DISTAL LOWER LEG}

The use of distaly pedicled propeller perforator flaps in the reconstruction of defects in the foot and distal lower leg accompanied by exposure of tendons, bone, and/or hardware represents a relatively new achievement, and was possible by revisiting vascular anatomy and extensive clinical experience, which confirmed their reliability and safety in achieving the goals of lower leg reconstruction.

\section{Anatomical considerations}

All three major vessels in the lower leg - posterior tibial, anterior tibial, and peroneal arteries - and also the descending genicular artery and the popliteal artery give perforator vessels able to ensure the survival of a flap. As showed by Geddes et al. [40], the skin of knee and leg represents $34 \%$ of the integument of lower extremity, and is blood supplied through about $30 \pm 13$ perforators, with a diameter of $0.7 \pm 0.2 \mathrm{~mm}$. They realize five vascular territories, organized as a series of four longitudinal rows within the intermuscular septa of the lower leg [40,42] (Fig. 1).

The descending genicular artery contributes through its superficial branch, the saphenous artery, to the blood supply of a territory over the medial aspect of the knee, the pes anserinus, and the medial head of the gastrocnemius muscle. It anastomoses anteriorly with the anterior tibial artery, posteriorly with the sural artery, and inferiorly with the posterior tibial artery.

The popliteal artery supplies a large territory over the popliteal region and the superior part of the posterior aspect of the lower leg, through either its superficial and/or deep sural branches. The deep medial and lateral sural arteries supply the gastrocnemius, soleus and plantaris muscles. From the lateral head of gastrocnemius emerges generally only one musculocutaneous perforator, while from the infero-medial part of the medial head emerge 2-3

\section{Fig. 1. The vascular territories of the lower leg}

The small stars represent the main distribution of perforators in each territory. SSA, superficial sural artery; DGA, descending genicular artery; ATA, anterior tibial artery; PTA, posterior tibial artery; PA, peroneal artery.

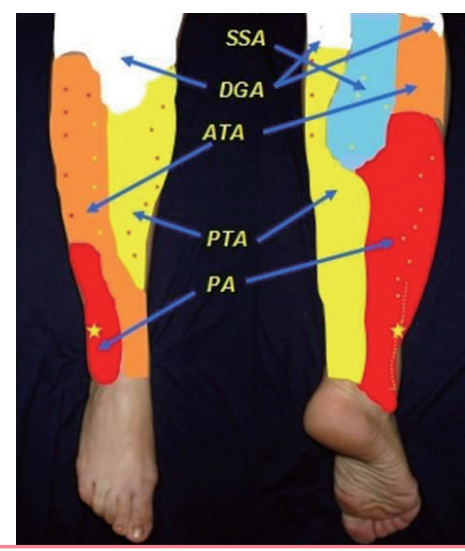

perforators, but their number can be more numerous if the superficial sural arteries are absent. From the two superficial sural arteries, one medial and one lateral, the medial one is the most important, has a diameter $\geq 1 \mathrm{~mm}$, and is accompanied by the small saphenous vein, medial sural cutaneous nerve, and sural nerve. The territory of all these arteries anastomoses inferiorly with the posterior tibial artery, medially with the descending genicular artery, and laterally with the peroneal and anterior tibial arteries.

The posterior tibial artery is the largest branch of the popliteal artery, and supplies $10 \%$ of the integument of the lower leg, the tibia and soleus, flexor digitorum longus, and tibialis posterior muscles. According with Geddes et al. [40], it gives about $10 \pm 4$ cutaneous perforators, but other authors found a number of 3 to $5[48,58]$. Those perforators with a diameter of about $1 \mathrm{~mm}$ $[40,48,58,94]$ are the largest of the lower leg, particularly in the middle third, in the septum between flexor digitorum longus and soleus, where they can reach a diameter up to $1.5 \mathrm{~mm}$ $[42,95]$. Some authors found the greatest distribution of perforators from 5 to $14 \mathrm{~cm}$ above the internal malleolus $[18,48,58]$, but Schaverien and Saint-Cyr [42] described three clusters (4 to $9 \mathrm{~cm}, 13$ to $18 \mathrm{~cm}$, and 21 to $26 \mathrm{~cm}$ from the intermalleolar line), each one with $23 \%$ of the total number of perforators and with at least one perforator in each cluster in $80 \%$ of cases. However, the perforators with the largest caliber are in the proximal two-thirds, and occasionally some of them can appear through the peroneal septum [56]. A very constant septocutaneous perforator is found approximately $5 \mathrm{~cm}$ above the medial malleolus [14]. The perforators are predominantly septocutaneous $[42,96]$, but musculocutaneous perforators are also well represented through the medial, posterior, and lateral aspects 
of the soleus, contributing to the supply of the skin around the Achilles tendon region $[40,94]$. There are anastomoses between the upper perforators with the descending genicular artery, and over the tibial crest with perforators of the anterior tibial artery [40], but also distally, where contribute through their terminal branches together with branches from the anterior tibial artery and peroneal artery to the formation of a collateral vascular network at the ankle region [14]. All perforator arteries have two venae comitantes $[42,55]$. The venae comitantes in the proximal two-thirds arise from both the venae comitantes of the posterior tibial artery and the long safenous vein, while in the distal third they arise only from the venae comitantes of the posterior tibial artery.

The anterior tibial artery supplies a territory of about $187 \pm 66$ $\mathrm{cm}^{2}$ through $6 \pm 3$ musculocutaneous and septocutaneous perforators, with a diameter between $0.6 \pm 0.2 \mathrm{~mm}$, and with a superficial length of about $29 \pm 13 \mathrm{~mm}$ [40]. The proximal perforators are the largest, and appear at 21 to $26 \mathrm{~cm}$ proximal to the intermalleolar line, between the tibia and tibialis anterior muscle and within the septa between the extensor digitorum longus and the peroneus longus muscles and between the tibialis anterior and extensor digitorum longus muscles, while the distal perforators are smaller, emerge between the tendons of the muscles of the anterior compartment, and are mainly found at 4 to $9 \mathrm{~cm}$ proximal to the intermalleolar line [42]. Proximally, one of the main branches of the anterior tibial artery, the recurrent tibial artery, anastomoses with the lateral inferior genicular artery and/or the descending genicular artery [40]. Over the tibial surface is realized a network of anastomoses between perforators of the anterior and posterior tibial arteries [40]. Distally, the anterior tibial artery gives 1-2 perforators just above the extensor retinaculum, and then gives off an anterolateral and an anteromedial branches to supply the skin over the anterior aspect of both malleola [14]. Anastomoses with branches from the peroneal and posterior tibial artery are realized at the ankle level [14].

The peroneal artery supplies 5\% of the integument of the lower leg, including the skin of the lateral leg and that around the Achilles tendon, together with the posterior tibial artery, the fibula, and the peroneal muscles, through $5 \pm 2$ musculocutaneous and septocutaneous perforators of $0.8 \pm 0.2 \mathrm{~mm}$ diameter $[40,56,94,97,98]$, with an average of 4.8 , and which are located posterior to the fibula [59]. The perforators predominate in the middle third of the lower leg, at 13 to $18 \mathrm{~cm}$ proximal to the lateral malleolus [42]. The musculocutaneous perforators appear through soleus and/or peroneus longus muscles, while the septocutaneous perforators emerge distally through the septum between flexor hallucis longus and peroneus brevis [42]. A very constant and large perforator passes anteriorly through the in- terosseous membrane approximately $5 \mathrm{~cm}$ above the lateral malleolus, and divides into an ascending and a descending branch $[14,40]$. The ascending branch anastomoses with the superficial peroneal artery, forming an anterolateral arterial chain, while the descending branch anastomoses with the anterolateral branches of the anterior tibial artery. The percentage of musculocutaneous and septocutaneous perforators has considerable differences in various studies: Heitmann et al. [59], 34\% musculocutaneous and 66\% septocutaneous; Yoshimura et al. [56], 71\% musculocutaneous and 29\% septocutaneous; Beppu et al. [97], 38\% musculocutaneous and $62 \%$ septocutaneous.

To conclude, according with Schaverien and Saint-Cyr [42], the distal to proximal distribution of the perforators in the lower leg is as follows: 1) in the 4 to $9 \mathrm{~cm}$ interval, perforators from both the anterior and posterior tibial arteries, but also 1-2 well represented perforators of the peroneal artery $[14,40] ; 2)$ in the 13 to $18 \mathrm{~cm}$ interval, perforators from both the peroneal and posterior tibial arteries; 3 ) in the 21 to $26 \mathrm{~cm}$ interval, perforators from both anterior and posterior tibial arteries.

\section{Flap design and harvesting technique of propeller per- forator flaps in the lower leg}

As mentioned, the preoperative detection of the perforators in the distal lower leg is useful, but not mandatory, because of the relatively superficial location of the main vessels, which can generate false positive or negative signals. The identification and isolation of a patent perforator can be very easily done intraoperatively through careful dissection, considering the defects' needs [46,91-93] (Fig. 2).

For the beginning, only one edge of the future flap is incised (Fig. 2B), and this incision must be not only the limit of the planned flap, but also of a possible alternative flap, if a suitable perforator isn't found $[46,87,90-92]$. The incision should be made up to or deep to the deep fascia, and is followed by either suprafascial or subfascial dissection under magnification and all the identified perforators are preserved (Fig. 2B). All through dissection, the perforators must be humidified with lydocaine to prevent spasm. If two adjacent perforators with same characteristics are found, it's better to keep both of them until the flap's dissection is completed and the tourniquet released. Then, after alternative clamping, it is possible to ligate one of them. Once the best perforator(s) is chosen, according with its location, size, suitability to sustain the flap, number of venae comitantes, course and orientation, the definitive design of the flap is accomplished. First, the long axis of the flap has to be orientated in the long axis of the leg. To the distance between the perforator and the distal edge of the defect $1-2 \mathrm{~cm}$ are added, and the resulting value is transposed proximally to the skin which will cover the 


\section{Fig. 2. Peroneal artery propeller perforator flap}

(A) Peroneal artery propeller perforator flap technical details for posttraumatic supramalleolar lateral ulceration in a patient with venous insufficiency-preoperative aspect. (B) Exploratory incison, with identification and isolation of a peroneal perforator $8 \mathrm{~cm}$ above the peroneal malleolus. (C) The incision of the entire flap is completed, and the flap is raised and ready to be rotated. (D) Final aspect of the flap and of the donor-site partially direct closed and partially grafted.
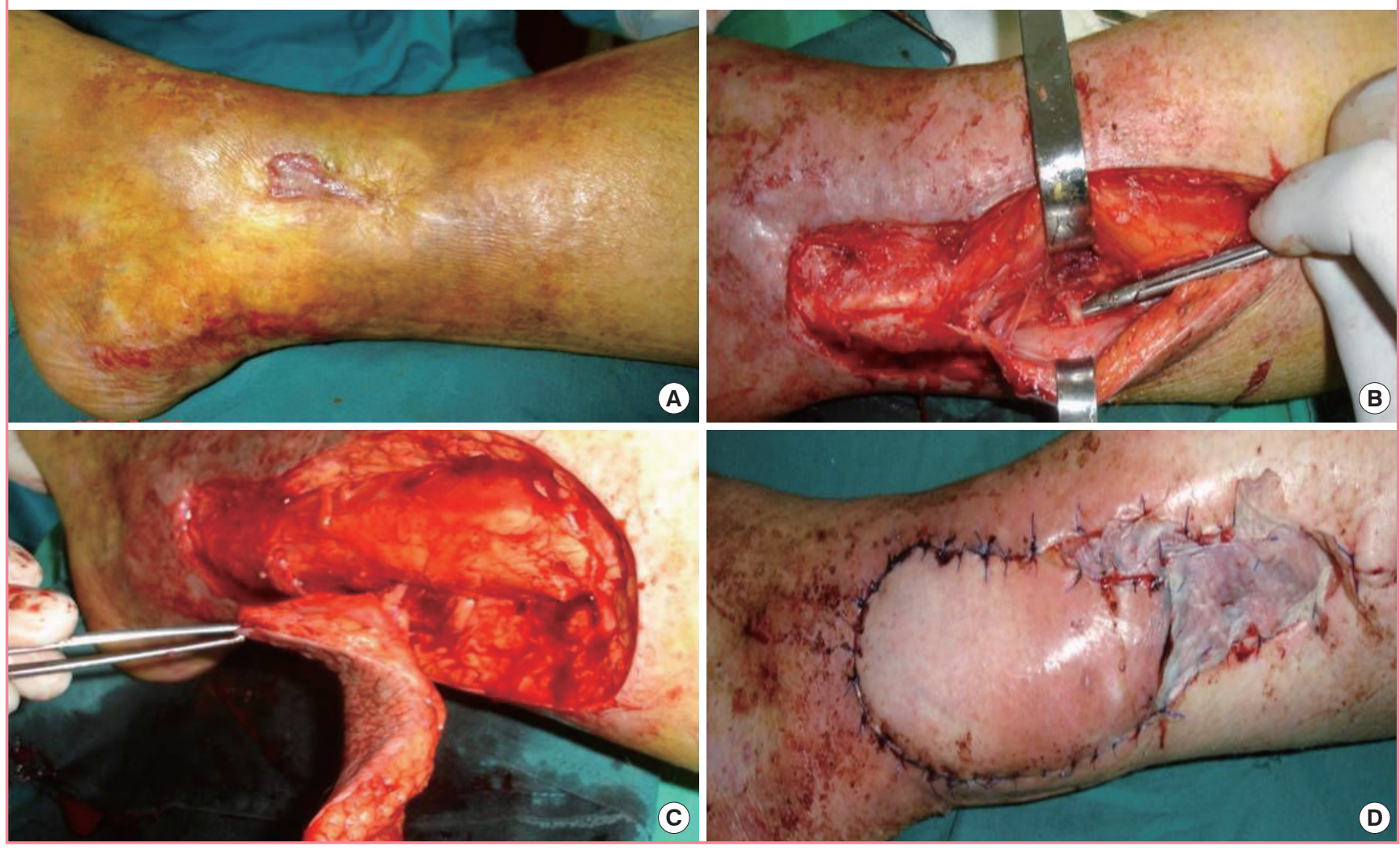

defect, ensuring the flap's comfortable inset, without any tension on the pedicle. Similar, to the width of the defect is added 0.5$1 \mathrm{~cm}$ to allow the closure without tension. Then, after enlarging the perforator foramen using a longitudinal fascial incision, the chosen perforator is cleared retrograde of all muscular branches and fascial strands for at least $2 \mathrm{~cm}$, but no longer than needed for optimal flap's rotation (Fig. 2B). Now, the incision around the flap and the harvesting (Fig. 2C) can be completed, but it's not yet rotated into the defect. If the perforator doesn't pulsate after releasing the tourniquet, it's better to leave the flap in its original position for 10-15 minutes to allow its reperfusion and the perforator's spasm disappearance. The flap can be rotated in a clockwise or counter-clockwise direction, function of the angle between the proximal long axis of the flap and the defect, and attention should be paid to choose the right rotational direction to avoid kinking of the vessels. The donor site shouldn't be closed under big tension, which can reduce the flap's blood supply by compressing the source vessel, and also can induce swelling of the distal leg. If primary closure isn't possible, the donor-site can be partially directly sutured, and the remaining defect skin grafted (Fig. 2D).

The use of propeller perforator flaps in distal lower leg allow them the coverage of small and medium size defects, but their dimensions have to be sometimes sensibly larger to cover these defects. That explains the large dimensions of flaps used by some surgeons. Rad et al. [7] successfully used a peroneal artery propeller perforator flap of $22 \times 8 \mathrm{~cm}$ to cover a defect of $6 \times 8 \mathrm{~cm}$ at the ankle and Achilles region, Koshima et al. [58] used a posterior tibial artery propeller perforator flap of $19 \times 13 \mathrm{~cm}$, and Quaba and Quaba [18] extended the length of the same flap to within $10 \mathrm{~cm}$ of the popliteal skin crease. We also extended proximally some of our flaps based on a single perforator, and the largest flap in lower leg in our experience was a posterior tibial artery propeller perforator flap of $28 \times 13 \mathrm{~cm}$ (Fig. 3). Sometimes it's possible to successfully harvest flaps of unusual design (Fig. 4). The explanation for both the big dimensions and unusual design of some flaps can be found in the perforasome concept of Saint-Cyr et al. [43], which underline the fact that hyperperfusion in a perforator allows the capture of multiple adjacent perforasomes through direct and indirect linking vessels. Or, it's well-known that in the proximal third of the lower leg are anastomoses between these arteries and the popliteal 
Fig. 3. Posterior tibial artery propeller perforator flap

(A) Very big flap of $28 / 13 \mathrm{~cm}$ based on a perforator of the posterior tibial artery in the middle third of the leg used for covering a distal third tibial open fracture. (B) Final aspect.
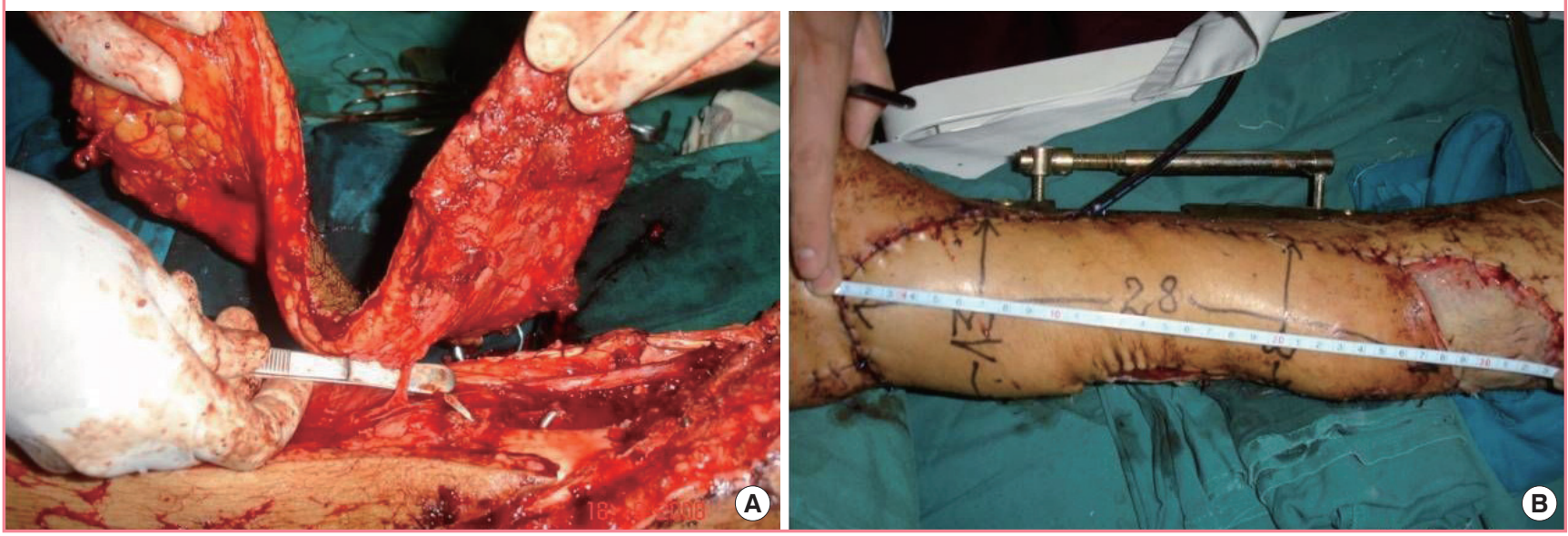

\section{Fig. 4. Peroneal artery propeller perforator plus flap}

(A) Infected stump after amputation in a patient with arteriosclerosis-preoperative aspect. (B) Peroneal artery perforator plus flap with unconventional design. (C) The flap covering the defect.
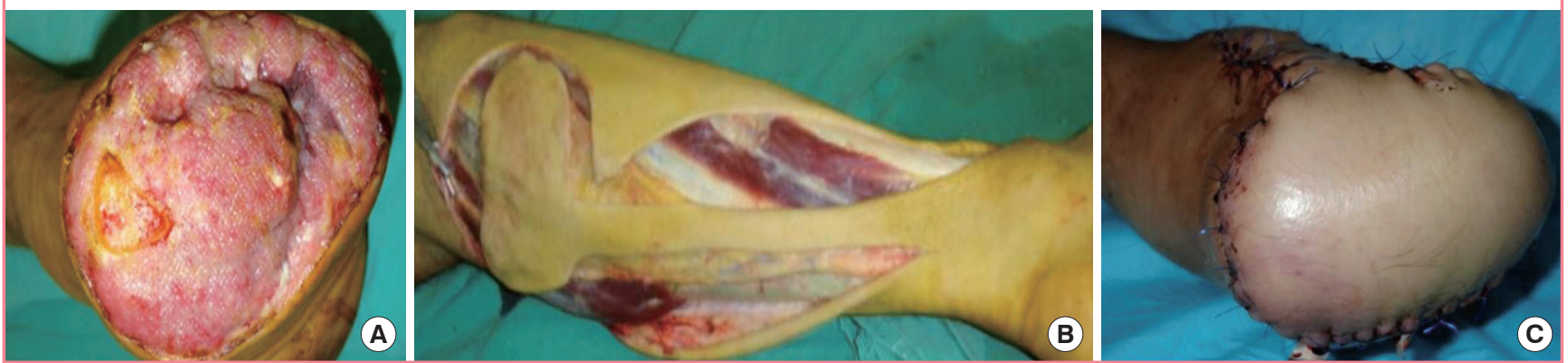

and descendent genicular arteries [40] (Fig. 1). To increase the viability of such big and unusually designed flap it's possible to design the flap as a perforator plus flap $[49,79,80]$. We also successfully used such flaps, but with a narrower base than originally described (Fig. 4).

\section{Indications and contraindications of propeller perfora- tor flaps in the lower leg}

Propeller perforator flaps in distal lower leg provide a valuable option in the reconstructive armamentarium, due to their main advantages. It is a relatively easy and less time consuming procedure, which is beneficial in elderly, multiple injured patients, or with a compromised general status. Besides the fact that the reconstruction can replace like-with-like by using tissues of similar texture, thickness, pliability, and color, this method avoid the complexity, the multiple surgical sites and the extra costs associated with free flaps and microsurgery. Moreover, in case of failure of a local perforator flap, alternative methods can be used, including free flaps. Similar to free flaps, the local perforator flaps reduce morbidity of the donor site, because the source artery and underlying muscle are preserved, and scars are limited to only one region. For defects less than $6 \mathrm{~cm}$ wide, the donor site can be primarily closed [21], but even bigger defects can be partially direct sutured. A significant drawback can be the cosmetic deficit related to the donor site, which formally contraindicates this procedure in women (Fig. 5). Another disadvantage is related to the fact that the perforator can be within the zone of injury, which can prejudice the viability of the flap.

Propeller perforator flaps are best suited for small and medium defects, and in trauma patients for defects without extensive avulsion and degloving injuries. An obvious contraindication of local perforator flaps are patients with peripheral vascular diseases and/or insulino-dependent diabetes $[18,21]$. However, because the peroneal artery is least likely to have atherosclerosis [99], or is the last affected, local perforator flaps based on this artery can be relatively safely harvested in elderly, atherosclerotic and diabetic patients (Figs. 4, 6).

The posterior tibial artery propeller perforator flap is indi- 


\section{Fig. 5. Anterior tibial artery propeller perforator flap}

(A) Posttraumatic defect over the peroneal malleolus in a young woman-the forceps indicates the extension of the lesion, with a distal pocket. (B) Final result, after covering the defect with a propeller perforator flap based on a very distal perforator of the anterior tibial artery; the donor-site was partially grafted.
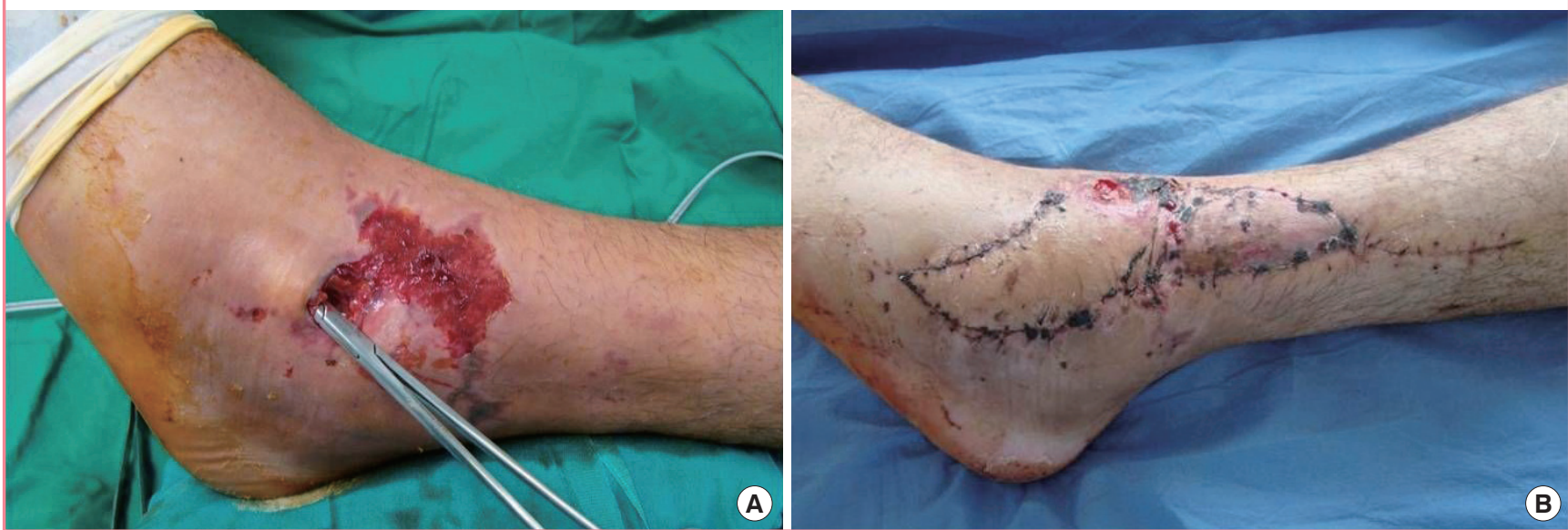

Fig. 6. Peroneal artery propeller perforator flap

(A) Calcaneal ulceration in a diabetic and atherosclerotic patient-preoperative aspect. (B) Long term result after covering with a peroneal artery propeller perforator flap based on a perforator found $5 \mathrm{~cm}$ above the lateral malleolus.
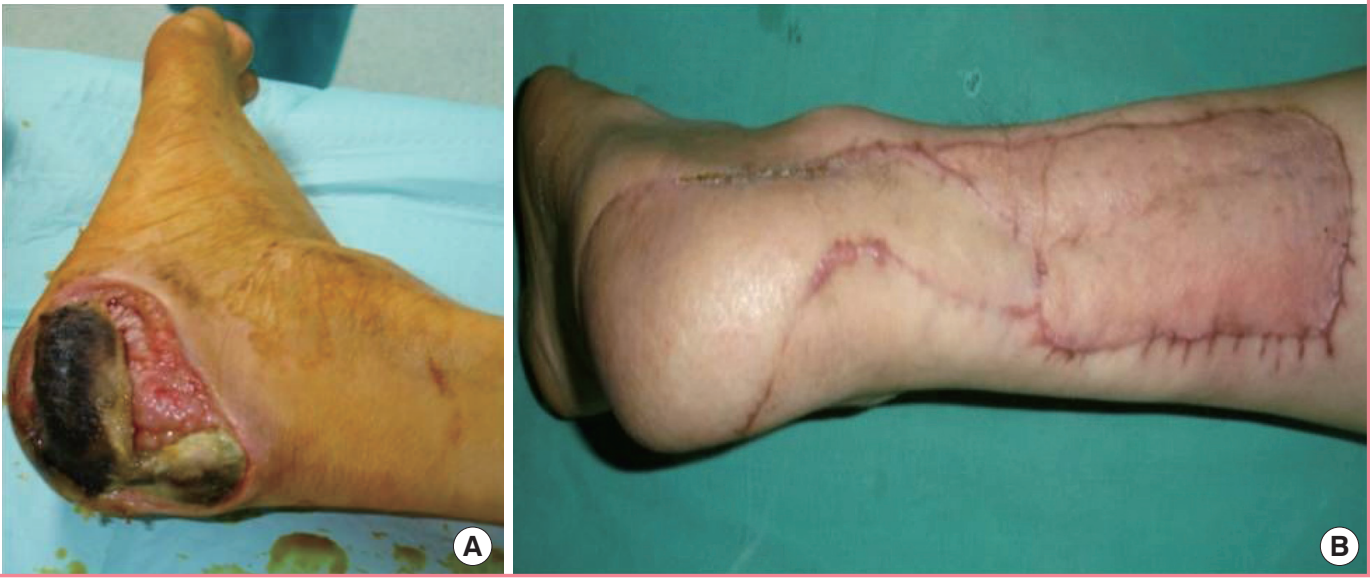

Fig. 7. Posterior tibial artery propeller perforator flap

(A) Ulceration with denuded Achilles tendon in a diabetic patient-preoperative aspect. (B) Final result after covering with a posterior tibial artery perforator flap based on a perforator found $5-6 \mathrm{~cm}$ above the internal malleolus.
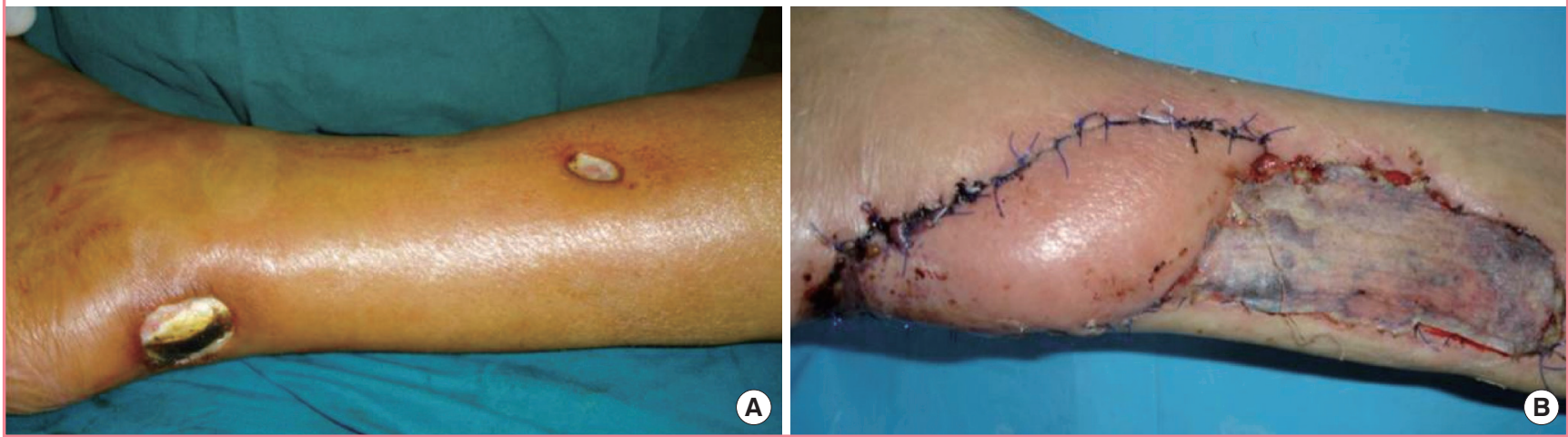

cated for defects over the pretibial and medial aspect of the distal leg, heel, medial malleolus, calcaneum, Achilles tendon, and dorsum of the foot. The best perforator to base the flap is located $5 \mathrm{~cm}$ above the medial malleolus [14] (Fig. 7), but with bigger 
flaps the larger perforators from the middle third of the leg can also be used (Fig. 3).

The anterior tibial artery propeller perforator flap is rarely used in the distal third of the lower leg, because of the small dimensions of the perforators. However, if a patent perforator is found, smaller flaps can be harvested to cover defects over the distal pretibial and anterior ankle region (Fig. 5).

The peroneal artery propeller perforator flap based on the most distal, but very well represented perforator located $5 \mathrm{~cm}$ above the lateral malleollus $[14,40]$ (Fig. 2), is very useful in covering the Achilles region, calcaneum, and the lateral malleolus, but, if very long flaps are harvested, is possible to cover also the plantar and dorsal aspect of the foot. Flaps based on more proximal perforators can also be used, but with the price of bigger flaps.

\section{COMPLICATIONS}

The venous congestion of the tip or of the entire flap is the most common complication, and is due to the insufficient flow in the perforator pedicle, either because of an inadequate selection of the perforator, or because of an insufficient dissection and clearing of the vascular pedicle, especially around the vein. Very rarely it happens to loose the entire flap, and from this point of view, in some cases is better to choose a local perforator flap, rather than a free flap. If a free flap is lost, everything is lost, while generally in a local perforator flap only the superficial part is lost, which means that the flap did its' job of covering the denuded anatomical elements. After debridement, the remaining part of the flap generally granulates very fast, and can be grafted.

If signs of congestion or ischemia are observed intraoperatively, a venous microsurgical anastomosis or the derotation of the flap in its original position can be attempted. If the vascular problems appear only postoperatively, the flap sometimes can be saved by removing the stitches, performing incisions, applying local heparinization or using leeches.

\section{CONCLUSIONS}

The propeller perforator flaps based on perforators from all three main axial vessels of the leg are very reliable in covering defects of the foot and distal lower leg, and in well selected cases can provide a simpler alternative to the more sophisticated free flaps.

\section{REFERENCES}

1. Byrd HS, Spicer TE, Cierney G 3rd. Management of open tibial fractures. Plast Reconstr Surg 1985;76:719-30.

2. Godina M. Early microsurgical reconstruction of complex trauma of the extremities. Plast Reconstr Surg 1986;78: 285-92.

3. Ninkovic M, Mooney EK, Kleistil T, et al. A new classification for the standardization of nomenclature in free flap wound closure. Plast Reconstr Surg 1999;103:903-14.

4. Georgescu AV, Ivan O. Emergency free flaps. Microsurgery 2003;23:206-16.

5. Levin LS. Foot and ankle soft-tissue deficiencies: who needs a flap? Am J Orthop (Belle Mead NJ) 2006;35:11-9.

6. McGregor IA, Morgan G. Axial and random pattern flaps. Br J Plast Surg 1973;26:202-13.

7. Rad AN, Singh NK, Rosson GD. Peroneal artery perforatorbased propeller flap reconstruction of the lateral distal lower extremity after tumor extirpation: case report and literature review. Microsurgery 2008;28:663-70.

8. Almeida MF, da Costa PR, Okawa RY. Reverse-flow island sural flap. Plast Reconstr Surg 2002;109:583-91.

9. McGregor IA, Jackson IT. The groin flap. Br J Plast Surg 1972;25:3-16.

10. McCraw JB, Furlow LT Jr. The dorsalis pedis arterialized flap. A clinical study. Plast Reconstr Surg 1975;55:177-85.

11. Torii S, Namiki Y, Hayashi Y, et al. Reverse-flow peroneal island flap for the reconstruction of leg and foot. Eur J Plast Surg 1988;11:26-31.

12. Liu K, Li Z, Lin Y, et al. The reverse-flow posterior tibial artery island flap: anatomic study and 72 clinical cases. Plast Reconstr Surg 1990;86:312-6.

13. Wee JT. Reconstruction of the lower leg and foot with the reverse-pedicled anterior tibial flap: preliminary report of a new fasciocutaneous flap. BrJ Plast Surg 1986;39:327-37.

14. Koshima I, Itoh S, Nanba Y, et al. Medial and lateral malleolar perforator flaps for repair of defects around the ankle. Ann Plast Surg 2003;51:579-83.

15. Ger R. The operative treatment of the advanced stasis ulcer. A preliminary communication. Am J Surg 1966;111:659-63.

16. Orticochea $\mathrm{M}$. The musculo-cutaneous flap method: an immediate and heroic substitute for the method of delay. $\mathrm{Br} \mathrm{J}$ Plast Surg 1972;25:106-10.

17. Ger R. The technique of muscle transposition in the operative treatment of traumatic and ulcerative lesions of the leg.J Trauma 1971;11:502-10.

18. Quaba O, Quaba AA. Pedicled perforator flaps for the lower limb. Semin Plast Surg 2006;20:103-11.

19. Hallock GG. Lower extremity muscle perforator flaps for lower extremity reconstruction. Plast Reconstr Surg 2004; 114:1123-30.

20. Kamath BJ, Joshua TV, Pramod S. Perforator based flap coverage from the anterior and lateral compartment of the 
leg for medium sized traumatic pretibial soft tissue defects: a simple solution for a complex problem. J Plast Reconstr Aesthet Surg 2006;59:515-20.

21. Jakubietz RG, Jakubietz MG, Gruenert JG, et al. The 180-degree perforator-based propeller flap for soft tissue coverage of the distal, lower extremity: a new method to achieve reliable coverage of the distal lower extremity with a local, fasciocutaneous perforator flap. Ann Plast Surg 2007;59:667-71.

22. Ponten $B$. The fasciocutaneous flap: its use in soft tissue defects of the lower leg. Br J Plast Surg 1981;34:215-20.

23. Haertsch P. The surgical plane in the leg. Br J Plast Surg 1981; 34:464-9.

24. Barclay TL, Cardoso E, Sharpe DT, et al. Repair of lower leg injuries with fascio-cutaneous flaps. Br J Plast Surg 1982;35: 127-32.

25. Cormack GC, Lamberty BG. Fasciocutaneous vessels. Their distribution on the trunk and limbs, and their clinical application in tissue transfer. Anat Clin 1984;6:121-31.

26. Manchot $C$. The cutaneous arteries of the human body. New York: Springer-Verlag; 1983.

27. Salmon M, Taylor GI, Tempest M. Arteries of the skin. London: Churchill Livingstone; 1988.

28. Taylor GI, Palmer JH. The vascular territories (angiosomes) of the body: experimental study and clinical applications. $\mathrm{Br}$ J Plast Surg 1987;40:113-41.

29. Taylor GI, Pan WR. Angiosomes of the leg: anatomic study and clinical implications. Plast Reconstr Surg 1998;102:599616.

30. Koshima I, Soeda S. Inferior epigastric artery skin flaps without rectus abdominis muscle. Br J Plast Surg 1989;42:645-8.

31. Kroll SS, Rosenfield L. Perforator-based flaps for low posterior midline defects. Plast Reconstr Surg 1988;81:561-6.

32. Song YG, Chen GZ, Song YL. The free thigh flap: a new free flap concept based on the septocutaneous artery. Br J Plast Surg 1984;37:149-59.

33. Koshima I, Kawada S, Etoh H, et al. Flow-through anterior thigh flaps for one-stage reconstruction of soft-tissue defects and revascularization of ischemic extremities. Plast Reconstr Surg 1995;95:252-60.

34. Koshima I, Urushibara K, Inagawa K, et al. Free tensor fasciae latae perforator flap for the reconstruction of defects in the extremities. Plast Reconstr Surg 2001;107:1759-65.

35. Koshima I, Nanba Y, Tsutsui T, et al. Perforator flaps in lower extremity reconstruction. Handchir Mikrochir Plast Chir 2002;34:251-6.

36. Angrigiani C, Grilli D, Siebert J. Latissimus dorsi musculocutaneous flap without muscle. Plast Reconstr Surg 1995; 96:1608-14.
37. Koshima I, Saisho H, Kawada S, et al. Flow-through thin latissimus dorsi perforator flap for repair of soft-tissue defects in the legs. Plast Reconstr Surg 1999;103:1483-90.

38. Kim JT, Koo BS, Kim SK. The thin latissimus dorsi perforator-based free flap for resurfacing. Plast Reconstr Surg 2001;107:374-82.

39. Hallock GG, Sano K. The medial sural MEDIAL GASTROCNEMIUS perforator free flap: an 'ideal' prone position skin flap. Ann Plast Surg 2004;52:184-7.

40. Geddes CR, Tang M, Yang D, et al. Anatomy of the integument of the lower extremity. In: Blondeel PN, Morris SF, Hallock GG, et al., editors. Perforator flaps: anatomy, technique \& clinical applications. St. Louis: Quality Medical Publishing, Inc.; 2006. p. 541-78.

41. Saint-Cyr M, Schaverien M, Arbique G, et al. Three- and four-dimensional computed tomographic angiography and venography for the investigation of the vascular anatomy and perfusion of perforator flaps. Plast Reconstr Surg 2008; 121:772-80.

42. Schaverien M, Saint-Cyr M. Perforators of the lower leg: analysis of perforator locations and clinical application for pedicled perforator flaps. Plast Reconstr Surg 2008;122:161-70.

43. Saint-Cyr M, Wong C, Schaverien M, et al. The perforasome theory: vascular anatomy and clinical implications. Plast Reconstr Surg 2009; 124:1529-44.

44. Lecours C, Saint-Cyr M, Wong C, et al. Freestyle pedicle perforator flaps: clinical results and vascular anatomy. Plast Reconstr Surg 2010;126:1589-603.

45. Rubino C, Coscia V, Cavazzuti AM, et al. Haemodynamic enhancement in perforator flaps: the inversion phenomenon and its clinical significance. A study of the relation of blood velocity and flow between pedicle and perforator vessels in perforator flaps. J Plast Reconstr Aesthet Surg 2006;59:636-43.

46. Georgescu AV, Matei I, Ardelean F, et al. Microsurgical nonmicrovascular flaps in forearm and hand reconstruction. Microsurgery 2007;27:384-94.

47. Parrett BM, Talbot SG, Pribaz JJ, et al. A review of local and regional flaps for distal leg reconstruction. J Reconstr Microsurg 2009;25:445-55.

48. El-Sabbagh AH. Skin perforator flaps: an algorithm for leg reconstruction. J Reconstr Microsurg 2011;27:511-23.

49. Lee BT, Lin SJ, Bar-Meir ED, et al. Pedicled perforator flaps: a new principle in reconstructive surgery. Plast Reconstr Surg 2010;125:201-8.

50. Hyakusoku H, Yamamoto T, Fumiiri M. The propeller flap method. Br J Plast Surg 1991;44:53-4.

51. Hallock GG. The propeller flap version of the adductor muscle perforator flap for coverage of ischial or trochanteric 
pressure sores. Ann Plast Surg 2006;56:540-2.

52. Pignatti M, Ogawa R, Hallock GG, et al. The “Tokyo” consensus on propeller flaps. Plast Reconstr Surg 2011;127:716-22.

53. Teo TC. Perforator local flaps in lower limb reconstruction. Cir Plast Iberlatinamer 2006;32:15-6.

54. Whetzel TP, Barnard MA, Stokes RB. Arterial fasciocutaneous vascular territories of the lower leg. Plast Reconstr Surg 1997;100:1172-83.

55. Carriquiry C, Aparecida Costa M, Vasconez LO. An anatomic study of the septocutaneous vessels of the leg. Plast Reconstr Surg 1985;76:354-63.

56. Yoshimura M, Shimada T, Hosokawa M. The vasculature of the peroneal tissue transfer. Plast Reconstr Surg 1990;85: 917-21.

57. Hwang WY, Chen SZ, Han LY, et al. Medial leg skin flap: vascular anatomy and clinical applications. Ann Plast Surg 1985; 15:489-91.

58. Koshima I, Moriguchi T, Ohta S, et al. The vasculature and clinical application of the posterior tibial perforator-based flap. Plast Reconstr Surg 1992;90:643-9.

59. Heitmann C, Khan FN, Levin LS. Vasculature of the peroneal artery: an anatomic study focused on the perforator vessels. J Reconstr Microsurg 2003;19:157-62.

60. Masia J, Moscatiello F, Pons G, et al. Our experience in lower limb reconstruction with perforator flaps. Ann Plast Surg 2007;58:507-12.

61. Tos P, Innocenti M, Artiaco S, et al. Perforator-based propeller flaps treating loss of substance in the lower limb. J Orthop Traumatol 2011;12:93-9.

62. Jiga LP, Barac S, Taranu G, et al. The versatility of propeller flaps for lower limb reconstruction in patients with peripheral arterial obstructive disease: initial experience. Ann Plast Surg 2010;64:193-7.

63. Pignatti M, Pasqualini M, Governa M, et al. Propeller flaps for leg reconstruction. J Plast Reconstr Aesthet Surg 2008; 61:777-83.

64. Niranjan NS, Price RD, Govilkar P. Fascial feeder and perforator-based V-Y advancement flaps in the reconstruction of lower limb defects. Br J Plast Surg 2000;53:679-89.

65. Wong CH, Cui F, Tan BK, et al. Nonlinear finite element simulations to elucidate the determinants of perforator patency in propeller flaps. Ann Plast Surg 2007;59:672-8.

66. Taylor GI, Doyle M, McCarten G. The Doppler probe for planning flaps: anatomical study and clinical applications. $\mathrm{Br}$ J Plast Surg 1990;43:1-16.

67. Morris SF, Taylor GI. Predicting the survival of experimental skin flaps with a knowledge of the vascular architecture. Plast Reconstr Surg 1993;92:1352-61.
68. Dhar SC, Taylor GI. The delay phenomenon: the story unfolds. Plast Reconstr Surg 1999;104:2079-91.

69. Bhattacharya V, Deshpande SB, Watts RK, et al. Measurement of perfusion pressure of perforators and its correlation with their internal diameter. Br J Plast Surg 2005;58:759-64.

70. Panse NS, Bhatt YC, Tandale MS. What is safe limit of the perforator flap in lower extremity reconstruction ? Do we have answers yet? Plast Surg Int 2011;2011:349357.

71. Blondeel PN, Beyens G, Verhaeghe R, et al. Doppler flowmetry in the planning of perforator flaps. Br J Plast Surg 1998;51:202-9.

72. Yu P, Youssef A. Efficacy of the handheld Doppler in preoperative identification of the cutaneous perforators in the anterolateral thigh flap. Plast Reconstr Surg 2006;118:928-33.

73. Khan UD, Miller JG. Reliability of handheld Doppler in planning local perforator-based flaps for extremities. Aesthetic Plast Surg 2007;31:521-5.

74. McCraw JB, Myers B, Shanklin KD. The value of fluorescein in predicting the viability of arterialized flaps. Plast Reconstr Surg 1977;60:710-9.

75. Morykwas MJ, Hills H, Argenta LC. The safety of intravenous fluorescein administration. Ann Plast Surg 1991;26: 551-3.

76. Eren S, Rubben A, Krein R, et al. Assessment of microcirculation of an axial skin flap using indocyanine green fluorescence angiography. Plast Reconstr Surg 1995;96:1636-49.

77. Holm C, Mayr M, Hofter E, et al. Intraoperative evaluation of skin-flap viability using laser-induced fluorescence of indocyanine green. Br J Plast Surg 2002;55:635-44.

78. Matsui A, Lee BT, Winer JH, et al. Real-time intraoperative near-infrared fluorescence angiography for perforator identification and flap design. Plast Reconstr Surg 2009;123:125e-7e.

79. Mehrotra S. Perforator-plus flaps: a new concept in traditional flap design. Plast Reconstr Surg 2007;119:590-8.

80. Parrett BM, Winograd JM, Lin SJ, et al. The posterior tibial artery perforator flap: an alternative to free-flap closure in the comorbid patient. J Reconstr Microsurg 2009;25:105-9.

81. Saint-Cyr M, Schaverien M, Rohrich RJ. Preexpanded second intercostal space internal mammary artery pedicle perforator flap: case report and anatomical study. Plast Reconstr Surg 2009; 123:1659-64.

82. Saint-Cyr M, Schaverien MV, Rohrich RJ. Perforator flaps: history, controversies, physiology, anatomy, and use in reconstruction. Plast Reconstr Surg 2009; 123:132e-45e.

83. Asko-Seljavaara S. Free style free flaps. Seventh Congress of the International Society of Reconstructive Microsurgery; 1983 Jun 19-30; New York, NY.

84. Quaba AA, Davison PM. The distally-based dorsal hand 
flap. Br J Plast Surg 1990;43:28-39.

85. Mardini S, Tsai FC, Wei FC. The thigh as a model for free style free flaps. Clin Plast Surg 2003;30:473-80.

86. Wei FC, Mardini S. Free-style free flaps. Plast Reconstr Surg 2004;114:910-6.

87. Wallace CG, Kao HK, Jeng SF, et al. Free-style flaps: A further step forward for perforator flap surgery. Plast Reconstr Surg 2009; 124:e419-26.

88. Yildirim S, Taylan G, Akoz T. Freestyle perforator-based V-Y advancement flap for reconstruction of soft tissue defects at various anatomic regions. Ann Plast Surg 2007;58:501-6.

89. D’Arpa S, Cordova A, Pirrello R, et al. Free style facial artery perforator flap for one stage reconstruction of the nasal ala. J Plast Reconstr Aesthet Surg 2009;62:36-42.

90. D’Arpa S, Cordova A, Pignatti M, et al. Freestyle pedicled perforator flaps: safety, prevention of complications, and management based on 85 consecutive cases. Plast Reconstr Surg 2011;128:892-906.

91. Georgescu AV, Capota I, Matei I, et al. The place of local/ regional perforator flaps in complex traumas of the forearm. J Hand Microsurg India 2009; 1:25-31.

92. Matei I, Georgescu A, Chiroiu B, et al. Harvesting of forearm perforator flaps based on intraoperative vascular exploration: clinical experiences and literature review. Microsur- gery 2008;28:321-30.

93. Lee GK. Invited discussion: Harvesting of forearm perforator flaps based on intraoperative vascular exploration: clinical experiences and literature review. Microsurgery 2008;28: 331-2.

94. Tang M, Mao Y, Almutairi K, et al. Three-dimensional analysis of perforators of the posterior leg. Plast Reconstr Surg 2009;123:1729-38.

95. Zhang X, Wang X, Wen S, et al. Posterior tibial artery-based multilobar combined flap free transfer for repair of complex soft tissue defects. Microsurgery 2008;28:643-9.

96. Wu WC, Chang YP, So YC, et al. The anatomic basis and clinical applications of flaps based on the posterior tibial vessels. Br J Plast Surg 1993;46:470-9.

97. Beppu M, Hanel DP, Johnston GH, et al. The osteocutaneous fibula flap: an anatomic study. J Reconstr Microsurg 1992;8:215-23.

98. Wei FC, Chen HC, Chuang CC, et al. Fibular osteoseptocutaneous flap: anatomic study and clinical application. Plast Reconstr Surg 1986;78:191-200.

99. Hansen T, Wikstrom J, Johansson LO, et al. The prevalence and quantification of atherosclerosis in an elderly population assessed by whole-body magnetic resonance angiography. Arterioscler Thromb Vasc Biol 2007;27:649-54. 